\title{
Why do Cultures Change? The Challenges of Globalization
}

\section{Alain Suberchicot}

\section{Q OpenEdition \\ 12 Journals}

\section{Electronic version}

URL: http://journals.openedition.org/transtexts/237

DOI: $10.4000 /$ transtexts.237

ISSN: 2105-2549

\section{Publisher}

Gregory B. Lee

\section{Printed version}

Date of publication: 1 December 2008

Number of pages: 5-17

ISSN: 1771-2084

\section{Electronic reference}

Alain Suberchicot, «Why do Cultures Change? The Challenges of Globalization», Transtext(e)s Transcultures 跨文本跨文化 [Online], 4 | 2008, Online since 20 September 2009, connection on 10 December 2020. URL : http://journals.openedition.org/transtexts/237 ; DOI : https://doi.org/10.4000/ transtexts. 237

(c) Tous droits réservés 


\title{
What Constitutes 'Context' in Sociocultural Research? How the Mongolian Experience Challenges Theory
}

\author{
PATRICK Dillon, PHIL BAYLISS, INES STOLPE, LiNDA BAYLISS
}

Sociocultural theory is a Western construct, an explanatory framework for cultural patterns associated with settled, largely urban, lifestyles. In Mongolia the majority of people are mobile pastoralists. The Mongolian situation challenges some fundamental premises of Western theory. In Western educational situations, structures, contexts and schemata are substantially pre-defined, and we talk about things as 'contextdependent', since context is something that can be described as the backdrop to behaviour. In Mongolia both meaning and context emerge from people's interactions with their environments and may subsequently be described. These are respectively relational and co-constitutional interpretations of situations. The interpretations are different, not oppositional or mutually exclusive. In this paper we present an ecological framework in an attempt to simultaneously embrace both interpretations. The purpose is: first, to foreground some co-constitutional interpretations and, where possible, to compare and contrast them with relational interpretations; second, to reframe them though a cultural ecological lens; and third, to use these comparisons and re-framings as a basis for discussing some of the issues arising from current Western involvement in development and education in Mongolia.

\section{Introduction}

"From the air, Mongolia looks like God's preliminary sketch for Earth, not so much a country as the ingredients out of which countries are made: grass, rock, water and wind. Undulating hills, smooth as felt, rolled away into grassy infinities. A river spilled a silver lace work of water across soft downs. The 
emptiness was startling. Mongolia made the sky, with its baroque clouds, seem crowded and fussy. A few trees appeared. Having stumbled into the wrong landscape, they clustered together in the lee of a hill, trying to keep out of the wind. For miles there were no roads, no towns, no buildings. The only sign of habitation were the occasional encampments of round white tents, which sprouted suddenly and mysteriously in the grass below like mushrooms." 1

This is how Stewart describes his arrival in Mongolia. His ideas are shaped by the image of Mongolia as an almost untouched country: nature is untamed, even human dwellings, 'mushrooms', are part of it. At first he calls the dwellings 'tents', thereafter they are called by the Mongolian name 'gers'. The perspective of the incoming other is further exemplified by the contrast of heaven and earth 'crowded with baroque clouds' [which happens only in summer] versus 'startling emptiness'. And the whole setting appears as a provisional arrangement - an impression that most outsiders have of Mongolia.

The notion of 'experience' in the title of this paper, is about contrast as well, as it refers to an outsider's perspective. The experience of Mongolia is one of challenge a challenge which questions assumptions and pre-suppositions about the relationships between people and their environments. The three of us from Exeter (Dillon, Bayliss and Bayliss) have been involved with Mongolia since 2006, working within a European Union Project for the professional development of teachers (the OUTREACH Project). Ines Stolpe is Lecturer in Mongolian Studies at Humboldt University. Since 1992, she has undertaken extensive linguistic and social science field research in Mongolia.

The OUTREACH project is about supporting the transition of education in rural settings following the collapse of Soviet influence in 1992 and Mongolia's subsequent entry into a free-market economy. Initially, post-1992, the proposed 'transition' resulted in increased poverty. Mongolia is the only state which has survived into the modern era "where nomadic people and a pastoral economy are co-terminous with a contiguous nation state" ${ }^{2}$ Pastoral herding is not just a form of economic behaviour, it is a way of life and helps shape a perception of surroundings which leads to an astonishing mobility of mind. For example, there is no 'real estate' but rather 'mobile property' (i.e. livestock). Livestock are an agency as such, with needs that have to be met by herders more frequently than would be necessary when maintaining 'dead property'. In order to intensify livestock production, herders have to extensify their radius of movement - the more often the

\footnotetext{
1 Stanley Stewart, In the Empire of Genghis Khaan, London, Flamingo, 2001, p. 85.

2 Larry Moses \& Stephen A. Halkovic, Introduction to Mongolian History and Culture, Bloomington, Indiana University Press, 1985.
} 
pasture is changed, the more efficient the pastoralism.

Mongolia has a rich and varied history. Chinggis (Genghis) Khaan (1162-1227) forged a nation from disparate groups of nomads across a landscape the size of Western Europe and created an empire which spread from the Yellow Sea in the East to Vienna in the West. The Mongolian Empire was in one sense a clash between nomadic and sedentary cultures. ${ }^{3}$ Allsen suggests that the Chinggis Empire allowed intercultural and intercontinental mixing of cultures and ideas. Although, as Weatherford argues, sedentary culture subsequently 'won', Mongolia is the only country left in the world where the 'nomadic' way of life, until the early 1980s, was sustained by the majority of the people. Despite ongoing urbanisation most of the Mongolians now living in towns have their biographical roots in pastoral herding. Hence, even urban settings are shaped by the nomadic in ways that seem unique in terms of frequent, if not omnipresent, interactions between the nomadic and the sedentary spheres of Mongolian society. As Khazanov observes:

"Although the main characteristic of all varieties of mobile pastoralism, in my opinion, is their specific economic specialization, it would be foolish to deny that this very specialization involves specific lifestyles, world views, cultural values, preferences and ideals. Pastoralism is not only a way of making a living; it is also a way of living." ${ }^{5}$

A legacy of the 'mixing of cultures' is the challenge it presents to simplistic notions of change, development and culture. Since 1992, Mongolia has been subject to a plethora of reports from various world development agencies. Non-Governmental Organisations supported Mongolia in drawing up 'Millennium Development Goals' in keeping with the aims of development of 'third-world countries'. Our work with teachers and communities in rural Mongolia, away from of Ulaanbaatar, the capital, has raised more questions than answers about the status and trajectories of education and development. In particular, it has caused us to review some of the assumptions underlying sociocultural theory, which is increasingly influential in the social sciences and near paradigmatic in education.

In this paper we look at the lenses on the world offered through sociocultural theory from both Western and Mongolian perspectives. Although the two perspectives have many things in common, they differ in the way they treat the context of situations, the relationships between behaviours and the settings in which

\footnotetext{
${ }^{3}$ Jack Weatherford, Genghis Khaan and the Making of the Modern World, New York, Three Rivers Press, 2004, p. 267.

4 Thomas T. Allsen, Culture and Conquest in Mongol Eurasia, London, Cambridge University Press, 2001.

5 Anatoly M. Khazanov, Nomads and the Outside World, Madison, The University of Wisconsin Press, 1994.
} 
they are expressed. If meaningful developmental and educational dialogues are to be had between Mongolia and Western nations then a framework is necessary that reconciles different contextualisations. We propose a cultural ecological framework, describe its essential characteristics, and explore its relevance to some contemporary issues.

\section{Sociocultural Theory and its Lenses on the World}

Sociocultural theory is a Western construct, an explanatory framework for cultural patterns associated with settled, largely urban, lifestyles. A sociocultural lens that is substantially relational is an important characteristic of this framework: situations, structures and schemata are defined relative to each other. We can legitimately talk about things as 'context-dependent' since context is something we define as the backdrop to behaviour. Context is typically seen as part of an historical continuum where the majority of people view the world diachronically, through long-term narratives that have a past, present and future. ${ }^{6}$ Inevitably, this leads to a degree of pre-specification for given situations relative to social institutions, which in a structural sense are enduring, even if their internal dynamics are subject to frequent change.

For example, the Western notion of a 'school' is built around physical and organisational infrastructure such as classrooms, curricula, pedagogies, examination systems and so on. For Mongolian nomads, the 'school', embodying the values of a sedentary culture, is seen as parallel to, and co-existent with, nomadic culture. The nomadic cosmology of the Daur people of north-eastern Mongolia is not related to abstract thinking about a world which can be separated from the self (and therefore transmitted through a school curriculum), but derived from '... direct personal engagement with objects and processes', from different ways of engaging with the world as 'landscapes'.7 This situates humanity in many versions of the world, as it were 'slatted' over one another, each one elaborated and extended in such a way as to offer different causal understandings of human society and personality. Thus, conventional social divisions are not the only means of differentiation; people, individually and collectively, are likenesses of the world outside. ${ }^{8}$

In Mongolia about half of the population does not lead a settled, largely urban lifestyle. The 'landscapes' inhabited by Mongolian nomads are constituted through

\footnotetext{
${ }^{6}$ Galen Strawson, "Against narrativity", Ratio, 2004, XVII.

7 Caroline Humphrey \& Urgunge Onon, Shamans and Elders, Oxford, Clarendon Press, 1996, p. 76.

${ }^{8}$ Humphrey, Onon, p. 105.
} 
their engagement with them. These landscapes are enacted or performed and brought into being through that engagement, rather than being seen as something pre-existing. In this sense, the Mongolian sociocultural lens has co-constitutional characteristics. Here both meaning and context emerge from people's interactions with their environment. Out of this both meaning and context may subsequently be described. In other words, situations are not necessarily pre-defined and outcomes are not necessarily pre-specified. In co-constitutional situations, things are reconfigured as needed and not in anticipation of something happening. Structures often emerge. This is reflected in the way that the culture encodes reality and history. Nomadic songs and dances are formed through what Taube \& Taube and Ong call 'rhapsodizing'. ${ }^{9}$ They are never simply 'reproduced'; rather they are created in performance which enables a co-constitution of form and content. Ong argues that this form of cultural production is characteristic of oral cultures and it requires an intimate relationship with the human lifeworld.

In both relational and co-constitutional situations there is also a subtle interplay between propositional knowledge and 'dynamic' knowledge. Propositional knowledge is typically structured hierarchically and encourages linear thinking where things have beginnings and ends and pathways follow trajectories or narratives, as in a dichotomous key where characteristics defined at one level depend on characteristics defined at an earlier level. Dynamic thinking happens 'in the moment'; it is typically lateral and addresses immediate problems. This is not simply an opposition between the 'what' of propositional knowledge and the 'how' of prescriptive and tacit knowledge, rather it is the relative utility of each in the formalised infrastructure of urban settings and the ever fluid environments of pastoral herding.

Van Oers identifies three explanations of meaning related to different notions of context offered through the Western sociocultural lens when applied to education. In each there is some separation of components if only as an analytical expediency (as in the explanatory device of thesis-antithesis-synthesis):

- Mental surrounding - context is provided by the learner in terms of what they already know, e.g. some existing relevant aspect of their structure of knowledge. This theory suggests that 'context' can be provided for the individual by effective cues, scaffolds and links between the new knowledge and the existing knowledge.

- Social surrounding - this relates to the idea that context is conceived of as a

9 Erika Taube \& Manfred Taube, Schamanen und Rhapsoden: Die geistige Kultur der alten Mongolei, Leipzig, Koehler E Amelang, 1983 ; Walter J. Ong, Orality and Literacy, London, Routledge, 1982, p. 59. 
meaningful situation i.e. a situation that 'makes sense' and consequently constitutes contexts for meaningful learning. In this theory, coherence arises from the individual's perception of the situation (context).

- Activity as context - The context of an activity is defined through an interaction of factors associated with the place where the activity is conceived, planned and realised, how it is experienced or interpreted by the people concerned, and the social and cultural norms governing these interactions. ${ }^{10}$

In contrast to the view of the 'externality' of context, the understanding of 'knowledge' being situated in a close engagement with the lifeworld, requires the co-constitution of 'context' through action and embodiment. The nomadic landscape is a 'smooth space' of different landscapes. ${ }^{11}$ The Mongolian's traditional understanding of space is different to the common Western idea that space is an empty place or container with nothing inside. Here space isn't 'an empty place', it is a 'super interrelation' defined by a potentiality. Potential is that which unifies the place, the time, the quality and the quantity of objects or phenomena. This potentiality is general and relative; it is abstract and real; it is nature and characteristics; it is moment and phenomena, it contains visible and invisible appearances which might change or take shape respectively when their time has come. An object or a phenomenon is 'potential', because it exists only in interrelation or interconnection with other objects or phenomena at a certain time. Time, in turn, is only to be recognised (and even imagined) through movement in space. An object or a phenomenon exists in the interaction between arga and bilig. Arga is the visible aspect of the potentiality of objects and phenomena, bilig is the invisible aspect. In Confucian thought these relate to yin and yang. Instead of 'objects' or 'phenomena' pre-existing (in an objective sense), they come into being through the interaction of arga and bilig. ${ }^{12}$

To apply these ideas to education, the 'smooth space' of the nomadic landscape (through the interaction of arga and bilig) results in understandings of human development as 'enlightenment' and the inherent potential to 'become human' through constant change. This process is seen as open and unpredictable; one knows when one has become 'enlightened' when one arrives at the state of humanity. For the Western way, where there is no sense of the co-constitutional aspects of arga and bilig, human development is seen in part to be an outcome of 'education' - something that is predictable and measurable. In contrast, the

\footnotetext{
10 Bert van Oers, “From context to contextualizing", Learning and Instruction, 8 (6), 1998, pp. 473-488.

11 Gilles Deleuze, Felix Guattari, A Thousand Plateaus, London, University of Minnesota Press, 1987.

12 Jadambaa, B., “Shuteltsen Bagtsrakhuin Uzel ba Khumuunii Khugjil” in Mongol Ulsyn Bolovsrolyn Ikh Surguul, Mongol-Daniin Khamtarsan 'Khuduugiin Surguuliin Khugiil', Tusul, Ulaanbaatar, 2007, pp. 31-60.
} 
Mongolian concept of education deals with the open-endedness of the educational process. The goal is not 'outcomes-based', but rather to be imagined as a dynamic balance, which enables the individual the flexibly to interact with his or her environment. It is seen as a process, not as a destination. In education, arga embraces not only the meaning of the visible but also of 'teaching methodology'. The goal of acting out arga is to enable the student to deal with the visible and the invisible, to develop what the Mongolians call 'an eye for the invisible', the potentiality. ${ }^{13}$

\section{A Cultural Ecological Lens}

Pursuing the metaphor of 'landscape', the Western sociocultural lens, in situations when context is given, is analogous to driving through a landscape - the route is determined and signposted. We are concerned with destinations, not in the travelling. The Mongolian sociocultural lens, in situations where context cannot be taken for granted, is analogous to being in a landscape - the way is determined by enacting the journey. In a very practical sense, there are few roads in the Mongolian countryside and way finding is dependent on judgement and enacting the context of the journey. The destination is 'over there' and is indeterminate. In order to navigate the nomad must negotiate the smooth space; one cannot follow a map. It is necessary to ask the way while one is on the way, not before the journey. The landscape never behaves as is implied in the static representation of a map: dust storms, mud flows, changes in the courses of rivers are forever, and sometimes very rapidly, changing its contours. Even modern geographical positioning systems are of little help: for example, they do not show crossing points at rivers which will periodically move as environmental conditions change. Being in a landscape is a defining characteristic of nomadicism.

It is important to emphasise that we are not dealing with absolutes or dualities. The relational and co-constitutional sociocultural lenses are different, not oppositional or mutually exclusive. The challenge is to find a framework that accommodates both. Dillon has proposed an ecological approach to culture that is flexible and adaptive and thus can simultaneously embrace different stances. ${ }^{14}$

\footnotetext{
13 Ines Stolpe, “'Bolovsrol', 'surgan khümüüjil' gedeg ügsiin ukhagdakhuun” [On the meaning of Mongolian educational terms] in Ministry of Education, Culture and Sciences, Mongolian Academy of Sciences; National Association of Mongol Studies; Mongolian State University of Education (Em.): Gadaadyn Zaluu Mongol Sudlaach Erdemtdiin Zuny Surguliin Iltgeliin Emchetgel, Ulaanbaatar, Mongol Sudlalyn Ündesnii Kholboo, 2005, pp. 11-14.

14 Patrick Dillon, "Creativity, wisdom and trusteeship - niches of cultural production" in A. Craft, H. Gardner \& G. Claxton (Eds.), Creativity and Wisdom in Education, Thousand Oaks, CA, Corwin Press,
} 
Some people object to framing culture 'ecologically' because they conceptualise it only in biological terms and thus see it as deterministic. This may be a legacy of the Darwinian view of environments selecting for organisms, or, more recently, of simplistic interpretations of arguments for a controlling influence for genes. Both of these misinterpretations fail to take account of the view that people and their environments are manifestations of each other, both relationally and coconstitutionally, one is not determining the other in the sense that "if proposition ' $a$ ' holds than proposition ' $b$ ' must follow.

The cultural ecological approach has also been hampered by two other misconceptions: first, a simplistic view of 'environment', which sees it only in terms of physical surroundings. We now regard human environments as holistic entities. They encompass the social and psychological as well as the physical. This means that ideas, beliefs, emotions - the whole spectrum of affective responses in humans, expressed and unexpressed, are part of a given environment, relative to and coconstituted with their social dynamics and physical characteristics. An environment can be singular ('my' environment, 'your' environment), inclusive ('our' environment) and exclusive ('their' environment). Second, the notion that if something is 'ecological' it is in a state of nature, and that only 'traditional' people are in a state of nature. Urban societies are as much ecologies as tribal groups living in a rain forest; judgements about their relative states of 'advancement' or 'progress' is meaningless. Both represent different constitutions of behaviour and environment.

Cultural ecology deals with the reciprocal relationship between people and their environments and thus offers a unifying frame for nature and culture. Broadly based in systems theory, cultural ecology recognises that the relationship between people and their environment is complex and adaptive. It incorporates notions of niche construction (people and environments in mutually transformative relationships), cultural dialogues (interactions between beliefs, ideas and behaviours, and the arena in which interactions take place between the people who hold or practice them) and coming into presence (a mechanism that accommodates the emergence and endurance of cultural patterns at varying scales and in varying timeframes).

Niches are constructed through people's traits and characteristics, broadly their behaviour, interacting with the components of their environment. Evolutionary biologists call the traits and characteristics features, and the components of the

2008, pp. 105-118. 
environment factors. ${ }^{15}$ Niche construction occurs when an organism modifies its feature-factor relationship. For the arguments made here, niche construction may be thought of simply as the mutually transformative interactions between individuals and groups and the environments in which the interactions take place.

In cultural ecology, cultural dialogues are an important mechanism through which feature-factor relationships are modified. Cultural dialogues involve interactions between information and processes associated with artefacts, tools, practices (e.g. designing, cooking), modes of communication (e.g. symbols, language), lifestyles and combinations of these (e.g. agriculture as a combination of tools, processes and lifestyle). Cultural dialogues are affected by and shape customs, norms and values. Cultural values adapt to opportunity: behaviours once unthinkable may subsequently, and surprisingly rapidly, become new norms. Thus every fixed assumption about society alters, at least if one takes a long enough perspective, and whatever forces prompt cultural change, all the values of society do not respond simultaneously. ${ }^{16}$ This fluidity of culture is reflected in co-constituting interactions between features and factors, behaviour and environment, thought and language, collectively giving rise to cultural patterns.

Cultural patterns will have novel properties that transcend the properties of their constituent parts, and behave in ways that cannot be predicted from the behaviour of the constituents. This is an important adjunct to niche construction. It helps avoid the criticism that ecological approaches are essentially deterministic. We can describe niches retrospectively, and niche construction enables us to make broad predictions about processes and directions of change, but precise configurations of the feature-factor relationship are emergent. Dillon \& Howe and Osberg \& Biesta call this coming into presence. ${ }^{17}$ Drawing on the work of Prigogine, the notion of perturbation in complex systems can be translated into the epistemological notion of 'incoming of the other'. ${ }^{18}$ What emerges both transcends (in that it is more than what came before) and subsumes (in that it includes what came before) the prior configurations. Reality is revealed through active construction, a coming into

\footnotetext{
15 John Odling-Smee, Kevin Laland, and Marcus Feldman, Niche construction: The Neglected Process in Evolution, Princeton, Princeton University Press, 2003.

16 Eric L. Jones, Cultures Merging: A historical and Economic Critique of Culture, Princeton, Princeton University Press, 2006.

17 Patrick Dillon \& Tony Howe, "An epistemology of presence and reconceptualisation in design education”, Interchange, 38 (1), 2007, pp. 69-88 ; Osberg, D. \& Biesta, G.J.J., “Complexity, knowledge and the incalculable: the epistemological implications of 'strong' emergence", Interchange, 38 (1), 2007, pp. 3551 .

18 Ilya Prigogine, The End of Certainty: Time, Chaos and the New Laws of Nature, London, The Free Press, 1997.
} 
presence, not fully unexpected, but of unpredictable configuration or actualisation, like in the potentiality of a mosaic.

A living system is defined as a variety of constituents, parts or events which coconstitute each other in such a way as to form a working unit or unified whole. A 'constituent' only becomes a constituent through its definition within the system. Conversely, the system can only be understood as a 'system' through the emergent properties of its constituents. Constituent parts do not 'exist' outside of systems, and 'systems' do not exist independently of their constituent parts. In other words, systems have an internal 'logic' that is a property of its interconnected sub-systems socio-logic, eco-logic, and so on. Systems theory is most commonly associated with the physical sciences where components and their interconnections may be specified precisely. Some physical situations may be modelled as equilibrium systems where external influences, perturbations, are accommodated through processes of positive feedback. Prigogine describes 'far from equilibrium' conditions that arise in some systems where responses to external influences give rise to new forms of self-organisation and emergent features. ${ }^{19}$ This is so in cultural ecological systems because human behaviour is inherently unpredictable.

Osberg \& Biesta have described this as a response to an incoming that is wholly 'other' to the responding system. ${ }^{20}$ The response both transcends and subsumes the prior configurations and thus there is a sense in which the past is represented in the present. The novelist Jean Rhys characterises the response as 'what was is': "The big idea-well, I'm blowed if I can be sure what it is. Something to do with time being an illusion, I think. I mean the past exists - side by side with the present, not behind it; that what was-is." 21 The new configuration is always one amongst a number of possible alternatives. In other words, there is always an unpredictable element to what emerges, and what emerges is not pre-determined. The 'chance', the alternatives that were not adopted by the system at each perturbation, cannot be 'read' from the system (i.e. - the alternatives that are not actualised are lost). Thus the history of the system cannot be read in linear, temporal terms. Prigogine calls this property 'time irreversibility'. The notion of time reversibility presents a conundrum: that the history of a system cannot be recovered accurately, yet we are continually producing robust histories. This apparent contradiction is resolved by drawing on Mead's idea that historical accounts of the past always give us a story of

\footnotetext{
19 Prigogine, 1997.

20 Osberg, D. \& Biesta, G.J.J., "Complexity, knowledge and the incalculable: the epistemological implications of 'strong' emergence", Interchange, 38 (1), 2007, 35-51.

21 Rhys cited in Anne B. Simpson, Territories of the Psyche: The Fiction of Jean Rhys, New York, Houndmills, 2005.
} 
the past from the perspective of the present (i.e. actualisation). ${ }^{22}$ There is no past that exists independently in itself; for each new present we must rewrite the past. This explains why people who have predominantly episodic (non-narrative) personalities are nevertheless comfortable within a culture that has strong historical narratives. ${ }^{23}$ Here, following Ong, the 'narrative' does not re-present the past as a facsimile, it re-creates it, through performing it. Once fixed within the (literate) approach of the sedentary, the past is literally a facsimile. ${ }^{24}$

Mongolia offers a complex mix of worldviews. Pegg observes, with reference to traditional music, dance and oral narrative: "these include mosaics of performance practices and discourses, rather than discrete and fixed sets of practices and beliefs." All are syncretic and overlap:

"Contemporary folk-religious practices are dialogic and mutually influencing reciprocal exchanges between human beings, nature-spirits, and gods of the universe, achieved by mimesis in performance... Topographical images are mapped in contours of melodies and dances; the body used to produce sounds and shapes in imitation of the environment. Such mimesis is an integral aspect of a sociospiritual process of exchange. Reciprocity is necessary, for, whether it is vocal reproduction of sounds heard in nature or using materials from nature in order to produce those sounds, something has been given that must be returned. Having returned the gift in performance, there is an expectation that the relationship of exchange will continue: the forces of nature will grant favors asked of them, whether it be giving animals in the hunt or exorcising evil spirits in the body or home." 25

This is a powerful co-constitutional interpretation, where both context and meaning emerge from the interaction between people and their environment. The only predefinable contextual element is performance; everything else comes into presence in the moment. The world is both 'real' and 'constructed'; it is both social and objective.

To 'belong to the world' means that one's primary way of relating to things is neither sensory and reflexive, nor cognitive or intellectual, rather bodily and skilful. Merleau-Ponty describes this as 'motor intentionality' - in grasping something we direct ourselves towards it and thus our action is intentional. ${ }^{26}$ But the action does not refer to the object (Bedeutung) by representing its objectives and determinate

\footnotetext{
22 Georges H., Mead, The Philosophy of the Present, La Salle, Illinois, Open Court, 1932.

23 Galen Strawson, "Against narrativity", Ratio, 2004, XVII.

${ }^{24}$ Ong, Orality and Literacy, 1982.

25 Carole Pegg, Mongolian Music, Dance, \& Oral Narrative, Seattle, University of Washington Press, 2001, p. 97.

26 Maurice Merleau-Ponty, Phenomenology of Perception, London, Routledge, 1962.
} 
features; it refers to it pragmatically in the light of contextual motor goals affected by one's body. In picking up a tea-cup to drink from it, one identifies it not by its objective location in space but by one's egocentric relation to one's hands; one grasps it in light of the goal of sipping from it. ${ }^{27}$ Thus, 'space' (both in the sense of 'objects', but also of 'landscape') 'elicits appropriate actions', that is it affords certain behaviours. The world is projected by the subject (Merleau-Ponty's 'intentional arc'), which integrates 'sensibility' and 'motility', 'perception' and 'action'. The 'intentional arc' and 'being-in-the-world' are neither purely first-person (subjective) nor purely third-person (objective), neither mental nor physical. They are existential structures prior to and more fundamental than these abstractions. ${ }^{28}$

If 'landscape' offers affordances to pastoral herders, then the 'performativity of space', requires the 'intentional arc' and 'being-in-the-world', but both of these are constrained by relationships between the 'Given' and the 'Made'. ${ }^{29}$ A parallel for the Given and the Made would be the visible and the potential. Accidental space (where the unexpected happens) and performative space are interrelated, but the Given constrains the Made. In oral cultures this is manifest in individuals interacting with other individuals in order to think, to remember, and to recall. Thus, language is a mode of action, not a countersign of thought among oral communicators and thought is nested in speech rituals not in texts. Oral communicators, in order to remember thoughts must think of them in ways which can be coded memorably. This is done through performance rituals which provide the vehicle and process, not the content. The 'event' from which a narrative emerges is reflected through the 'being-in-the-world' of the individual's (or a community's) enactment of the event.

Chinggis Khaan's life is documented in the partly legendary Secret History of the Mongols, but beyond there is no concrete 'trace'. Despite this he has left a huge spiritual heritage - where did this legacy come from? Weatherford argues that in order to understand Chinggis, we need an "archaeology of movement." 30 'Movement' is encoded by oral communicators through creating larger-than-life heroes. Colourless heroes cannot be remembered. Colourless personalities cannot survive oral mnemonics. In this discussion of space, Chinggis Khaan has moved from phenomenological (performed) space, through ordered space into phase-space and metaphor, because he has 'become the path' (the colourful larger than life hero who is memorable), through the archaeology of movement, the trace, not the

\footnotetext{
${ }^{27}$ Evan Thompson, Mind in Life: Biology, Phenomenology and the Science of Mind, Cambridge, MA, Harvard University Press, 2007, p. 247.

28 Thompson, p. 248.

29 Richard Rorty, Philosophy and the Mirror of Nature, London, Blackwell, 1980.

${ }^{30}$ Weatherford, Genghis Khaan and the Making of the Modern World, 2004.
} 
artefact. ${ }^{31}$ Chinggis Khaan exists as cartography of movement, not as a corporeality.

\section{Conclusion}

In relational educational systems experience of the real world is replaced increasingly by pedagogies based first on presentation and then re-presentation of the real world in the classroom. In the first, children are taught about a particular way of life, in the second, they are helped to acquire universal knowledge of a real world outside the school that is re-presented within the school. ${ }^{32}$ To some extent the direction of change in Mongolia (during socialist and post-socialist times) is similar. However, the school in country districts (soum) is the interface between 'an education' and the maintenance and coherence of the nomadic way of life. It provides centres of exchange for nomadic families through maintaining traditional cultural forms: song, dance, wrestling, archery and horse-racing. In this sense the school has become 'co-constituted' through enactment. Mongolians appreciate that school offers a 'surplus' which cannot be acquired in the educational settings of socialisation. They have 'Mongolised' those parts of the Western system that were culturally inappropriate, re-framed them by acting differently in practice. Despite this there is still a separation between the formal education offered in schools and the non-formal education associated with pastoral herding - if only through the fact that higher education is only available within urban centres and this requires translocation of students. There is thus a tension between relational and coconstitutional approaches.

The Buddhist/Lamaist tradition may offer some pointers about overcoming the tension. This tradition is based on sutras - the interface between the literate and the oral. The usual didactic is that the child learns Tibetan characters and reads the texts in Tibetan while learning some of them by heart. At the beginning this happens without knowing Tibetan language. The concept of learning by heart is thought to be useful as it leads to internalisation, and internalisation is seen as a precondition to 'dive' into the concepts. Once the child has assimilated the analytic knowledge contained in the word, the child then enters into dialogue with the teacher to develop the understanding of the word in order to develop wisdom. Wisdom is not contained in the sutras, in the logos, in the word; the lama provides the performance of the knowledge to bring into wisdom. The wisdom comes out of the walking, in conjunction with the lama. The teacher provides the performative

\footnotetext{
31 Weatherford.

32 Dillon \& Howe, “An epistemology of presence and reconceptualisation in design education", 2007.
} 
action to bring the knowledge into being (scaffolding, blossoming, unfolding, etc). ${ }^{33}$ Our work with OUTREACH was commissioned to provide 'professional development for rural teachers'. We have come to understand that what we have inadvertently been doing with Mongolian teachers is trying to change their approaches and structures from co-constituting to co-determining. One example: the programme is run at Master's level and the concept of 'intended learning outcomes' (ILO) proved difficult for Mongolian teachers (and academics) to grasp. The notion of an ILO is a Western construct based on pre-determined, measurable educational outcomes; this is at odds with the Lamaist tradition and the concept of arga; and bilig (see discussion of 'enlightenment' above).

Where tensions exist in the West between 'education' and 'becoming human', the Mongolian experience suggests a possibility of reframing the educational process as one of a 'journey in a landscape', rather than as a 'journey through a landscape'. If we follow the example of the Daur people of North-eastern Mongolia, who are situated in 'many versions of the world', then engaging through the 'divisions of the world' through likenesses could 'supersede those generated by purely social rules of identity, membership and succession'. ${ }^{34}$ We would like to see a relational and co-constitutional framework which is itself both relational and coconstitutional. In other words, an approach to development and education that is not 'impositional' nor 'transitional', but rather ecological in the sense that it is locally adaptive giving rise to niches of cultural production which 'reflect the particularity, subtlety, idiosyncrasy, and patina of locality at scales, at time frames, and through modes of organisation appropriate to those places and the enterprises within them'. .35

\footnotetext{
${ }^{33}$ Ines Stolpe, Schule versus Nomadismus? Interdependenzen von Bildung und Migration in der modernen Mongolei, Frankfurt am Main, Peter Lang, 2008.

${ }^{34}$ Humphrey \& Urgunge, Shamans and Elders, p. 85.

35 Patrick Dillon, "Creativity, wisdom and trusteeship - niches of cultural production”, pp. 105-118.
} 